\title{
The effect of annealing temperature on the structural, optical, and electrical properties of CdS films
}

\author{
Hulya Metin ${ }^{a)}$ \\ Mersin University, Department of Physics, Mersin, 33343 Turkey \\ Mehmet Ari \\ Erciyes University, Department of Physics, Kayseri, 38039 Turkey \\ Selma Erat \\ Laboratory for High Performance Ceramics EMPA—Swiss Federal Laboratories \\ for Materials Testing \& Research, CH-8600 Dübendorf, Switzerland; and \\ Department of Materials, Nonmetallic Inorganic Materials ETH Zurich-Swiss \\ Federal Institute of Technology, CH-8093 Zurich, Switzerland \\ Semra Durmuş and Mehmet Bozoklu \\ Erciyes University, Department of Physics, Kayseri, 38039 Turkey \\ Artur Braun $^{\text {b) }}$ \\ Laboratory for High Performance Ceramics EMPA-Swiss Federal Laboratories \\ for Materials Testing \& Research, CH-8600 Dübendorf, Switzerland
}

(Received 1 July 2009; accepted 8 September 2009)

Cadmium sulfide $(\mathrm{CdS})$ photocatalyst films were grown on glass by chemical bath deposition ( $\mathrm{pH} 9.4,70^{\circ} \mathrm{C}$ ) and then annealed in nitrogen from $423 \mathrm{~K}$ to $823 \mathrm{~K}$ in steps of $100 \mathrm{~K}$. The XRD crystallite size increases in a sigmoidal manner from $60 \mathrm{~nm}$ to $100 \mathrm{~nm}$ while the optical band gap energy decreases from $2.42 \mathrm{eV}$ to $2.28 \mathrm{eV}$. This trend is paralleled by the decreasing Urbach energy, but only up to $623 \mathrm{~K}$, where it increases again. This is the temperature where the Cd effectively surpasses the phase transformation from cubic to hexagonal, and the activation energy for electronic transport drops by a factor of nearly two.

\section{INTRODUCTION}

Cadmium sulfide $(\mathrm{CdS})$ is a II-VI semiconductor with an energy band gap $\left(E_{\mathrm{g}}\right)$ of $2.42 \mathrm{eV}$ in bulk materials at room temperature. ${ }^{1} \mathrm{CdS}$ has been known for many decades as a photocatalytic semiconductor material for solar hydrogen generation in the visible wavelength range. ${ }^{2}$ $\mathrm{CdS}$ is also one of the most promising materials for application in electronic and optoelectronic devices such as solar cells, photo sensors, laser materials, optical waveguides and nonlinear integrated optical devices. ${ }^{3-5}$ Polycrystalline $\mathrm{CdS}$ films are generally used in $\mathrm{CuInSe}_{2}$ (CIS) and CdTe solar cells as a window material for transmitting the light absorbed by CIS or CdTe, and also as the n-type material for p-n junction of solar cells. ${ }^{6}$ For increased efficiency of solar cells, a semiconductor with optimum band gap, low resistivity, and high absorption

Address all correspondence to these authors:

a)e-mail: hmetin@mersin.edu.tr

b)e-mail: Artur.Braun@empa.ch

This author was an editor of this focus issue during the review and decision stage. For the JMR policy on review and publication of manuscripts authored by editors, please refer to http:// www.mrs.org/jmr_policy

DOI: $10.1557 / J M R .2010 .0025$ coefficient is required. ${ }^{7}$ Naturally, many different synthesis processes have been tried such as spray pyrolysis, ${ }^{8,9}$ vacuum evaporation, ${ }^{10}$ metal organic chemical vapor deposition, ${ }^{11}$ and chemical bath deposition. ${ }^{7,12-22}$ Among these techniques, chemical bath deposition (CBD) is a low-cost and suitable technique to prepare high quality, well adhered film reproducibly. The deposition process is based on the slow release of sulfide ions via the controlled hydrolysis of thiourea $\left[\mathrm{SC}\left(\mathrm{NH}_{2}\right)_{2}\right]$ in an alkaline medium in the presence of a $\mathrm{Cd}$ salt and a chelating agent such as $\mathrm{NH}_{3}{ }^{23}$ The very high resistivity of the asdeposited films, typically on the order of $10^{6}-10^{7} \Omega-\mathrm{cm}$ at room temperature, ${ }^{13-24}$ has been attributed to lattice defects and dislocations, ${ }^{25-29}$ and can be reduced by annealing the film. The physical and chemical properties of not only CdS films but also most of the binary metal chalcogenides of II-VI semiconductors obtained by CBD critically depend on preparative parameters such as the source and concentration of metal and chalgonide ions, $\mathrm{pH}$ of the deposition solution, deposition time and temperature, and gas phase process parameters such as temperature, gas partial pressure, and the time of annealing.

The annealing temperature is one of the most important considerations affecting the physical properties such 
as the electrical and optical properties of thin films. In this work, CdS films of $2.8 \mu \mathrm{m}$ thickness were prepared by $\mathrm{CBD}$ at $70{ }^{\circ} \mathrm{C}$. The thermal treatment of the films was carried out in $\mathrm{N}_{2}$ to prevent oxidation of the film. The x-ray diffraction (XRD) was used to monitor the phase transformation, and $\mathrm{x}$-ray fluorescence (XRF) and scanning electron microscopy (SEM) were used for elemental analysis and to show the surface morphology. Optical absorption techniques and the four point probe technique were used to investigate the optical and electrical properties of the CdS films. The changes in optical and electrical properties depending on annealing temperature are discussed in detail and correlated with the changes in crystallographic structure.

\section{EXPERIMENTAL DETAILS}

The CdS films were deposited on a glass substrate $(75 \mathrm{~mm} \times 25 \mathrm{~mm} \times 2 \mathrm{~mm}$ ) using the CBD technique. Substrates were cleaned by following the procedure in Erat et al. ${ }^{30}$ and Metin et al. ${ }^{31}$ Aqueous solutions of $1 \mathrm{M}$ cadmium sulphate, 2.25 M hydrazine, 1.4 M thiourea, and 25\% $\mathrm{NH}_{3}$ were prepared without precipitation to deposit the $\mathrm{CdS}$ film. The film was deposited on the substrate by keeping it vertically in the beaker without stirring at $70{ }^{\circ} \mathrm{C}$ for $2 \mathrm{~h}$. This process was repeated seven times so as to increase film thickness, and the deposition solution was refreshed each time. After deposition, every film was rinsed in distilled water and methanol to remove the loosely adhered $\mathrm{CdS}$ particles on the surface and finally dried in air. The six as-deposited yellow CdS films with $2.8 \mu \mathrm{m}$ thickness were uniform, and adhered well to the substrates. Five of the films were annealed at $423 \mathrm{~K} \leq T \leq 823 \mathrm{~K}$ (in steps of $100 \mathrm{~K}$ ) with a $5 \mathrm{~K} / \mathrm{min}$ heating/cooling rate and $1 \mathrm{~h}$ dwell time using a horizontal tube furnace (Protherm PTF 15/75/ 610) with $100 \mathrm{~mL} / \mathrm{min}$ flowing $99.999 \%$ pure $\mathrm{N}_{2}$.

The CdS films were structurally characterized by $\mathrm{x}$-ray powder diffraction (XRD), in the range of diffraction angle $20^{\circ} \leq 2 \theta \leq 80^{\circ}$ in steps of $0.02^{\circ}$ with $40 \mathrm{kV}$ at $30 \mathrm{~mA}, \mathrm{CuK}_{\alpha 1}$ radiation $(\lambda=1.5406 \AA$ ) using Bruker AXS Advance D8 diffractometer. Elemental compositions of the films were measured using Panalitical Axios Advanced x-ray fluorescence (XRF). The microstructures of these films were characterized using a LEO 440 scanning electron microscope (SEM). The absorption spectra of the CdS films were measured by a using UV-visible spectrophotometer (SHIMADZU UV-1700) at room temperature in the wavelength range 190-1100 nm. The electrical measurements of the films were measured by the four-point probe technique. A Keithley 2400 sourcemeter was used to provide a constant current and the potential drop was measured with a Keithley 2700 multimeter through an interface card, controlled by a computer. The temperature of the films was controlled by a standard $\mathrm{K}$ type thermocouple.

\section{RESULTS AND DISCUSSION}

\section{A. Structural and morphological studies}

Figure 1 shows the XRD patterns of the as-deposited and annealed CdS films. The as-deposited and annealed CdS films at low temperature $(T<623 \mathrm{~K})$ exist in two crystalline phases: cubic (C) phase (zinc blende-type, JCPDS 06-0314) and hexagonal (H) phase (wurtize-type, JCPDS 10-0454), in line with the literature. $8,15,16,24,32-35$ Annealing leads to an overall improvement in the intensity of the peak heights, indicating that increasing annealing temperature increase the crystallinity of the film. By increasing the annealing temperature, the hexagonal phase becomes dominant and finally at $T=823 \mathrm{~K}$ the structure becomes $100 \%$ hexagonal phase. This phase transformation from cubic to hexagonal was earlier observed for the chemically deposited CdS films. ${ }^{13,18-22}$

We used the standard (111) $\mathrm{C}$ reflection at $2 \theta=26.68^{\circ}$ to calculate the crystallite sizes from the x-ray. As expected, increasing the annealing temperature causes a sharpening of the Bragg reflections, revealing an increase of the crystallinity of the film. The evaluation of the crystallite size was quantified by using Scherrer's formula,

$$
D_{h k l}=\frac{K \cdot \lambda}{\beta \cos \theta},
$$

where $K$ is the Scherrer constant, $\beta$ is the full width at half maximum (FWHM) of the Bragg reflection under

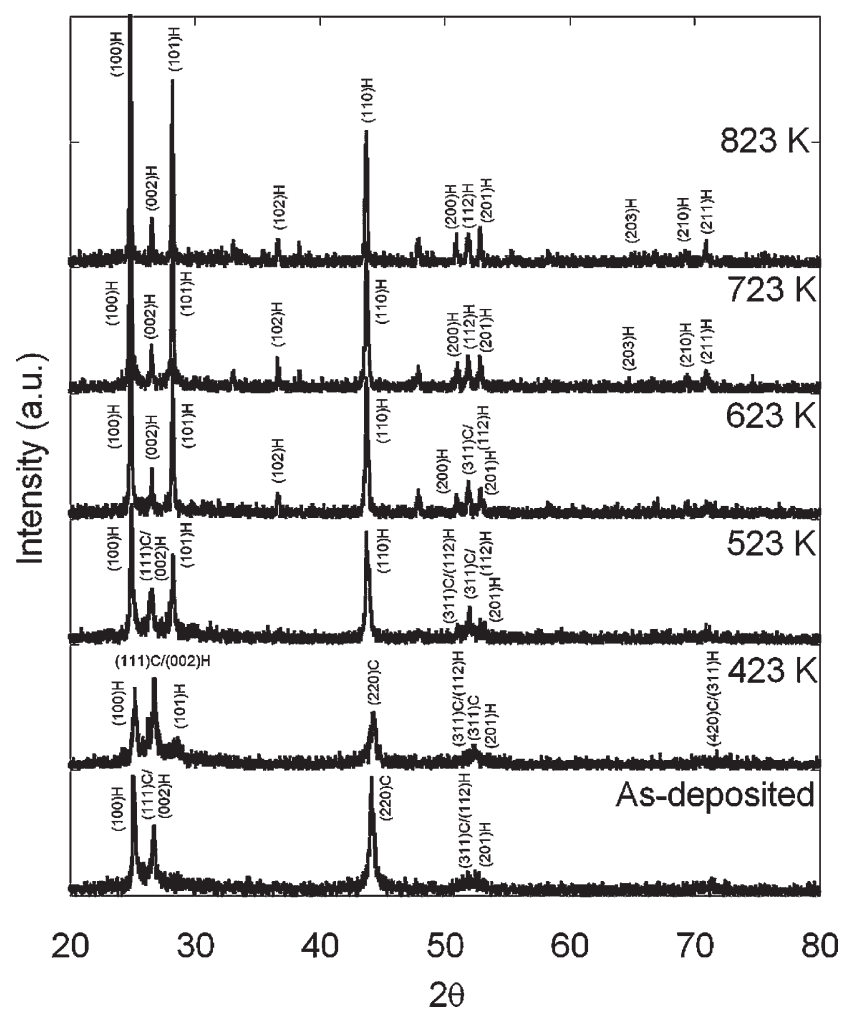

FIG. 1. X-ray diffractograms of the as-deposited and the annealed CdS films. 
TABLE I. The structural parameters of as-deposited and annealed CdS films. The films were grown at $70{ }^{\circ} \mathrm{C}$. These parameters were calculated using the $\mathrm{x}$-ray diffraction data.

\begin{tabular}{ccccc}
\hline \hline Annealing temperature $(\mathrm{K})$ & $\begin{array}{c}\text { FWHM }(\beta) \\
\left(\times 10^{-3} \mathrm{rad}\right)\end{array}$ & Crystallite size $(\mathrm{nm})$ & $\begin{array}{c}\text { Dislocation density } \\
\left(\times 10^{14} \text { lines } / \mathrm{m}^{2}\right)\end{array}$ & $\begin{array}{c}\text { Number of crystallites/unit } \\
\text { area }\left(\times 10^{16} \mathrm{~m}^{-2}\right)\end{array}$ \\
\hline As-deposited & 2.40 & 59 & 2.834 & 1.335 \\
$\left(\times 10^{-4}\right.$ rad $)$
\end{tabular}

consideration in radians, $\lambda$ is the wavelength of $x$-ray used, and $\theta$ is the Bragg angle. Equation (1) was used to calculate the crystallite sizes using $K=0.9$. The crystallite size of the as-deposited film was $59 \mathrm{~nm}$ and it increases by almost a factor of 2 with the annealing temperature. Furthermore, using these data, the dislocation density $\left(\delta=1 / D_{h k l}^{2}\right)$, the number of crystallites per unit surface area $\left(N=d / D_{h k l}^{3}\right.$, where $d$ is the film thickness $)$ and strain $(\varepsilon=\beta \cos \theta / 4)$ in the films were determined. The calculated structural parameters are listed in Table I. The defects like the dislocation density and strain in the films decrease as a result of annealing. This might be attributed to the improvement in crystallinity in the films with increasing annealing temperature.

Within the detection limit and the sensitivity range of the XRF instrument, no deviation from the nominal stoichiometry of CdS is found in our films.

The SEM micrographs of the as-deposited and the annealed CdS films (Fig. 2) show that the distribution of grains is not uniform throughout all the regions. However, the films cover the substrates well and are without any voids, pinholes, or cracks. The as-deposited film is made of platelet, oblate structured units of $1 \mu \mathrm{m}$ diameter and $\sim 150 \mathrm{~nm}$ thickness, on top of which there are some globules that look like cauliflowers, the leaves of which are made from the oblate unit. This particular morphology disappears for the film when annealed at $823 \mathrm{~K}$, suggesting a coarsening effect. While chemically deposited films typically may develop cracks at high temperature, our films do not show such cracking. But the film annealed at $823 \mathrm{~K}$ shows holes between the grains that were not apparent in the films annealed at lower temperatures.

\section{B. Optical properties}

The optical transmittance $(T)$ curves obtained at room temperature of the as-deposited and annealed CdS films are shown in Fig. 3 as a function of wavelength. There are two noteworthy changes with increasing annealing temperature in the transmission spectra. The first one is the decrease in the transmittance $(T=50 \%$ for asdeposited film while $T=5 \%$ for the annealed film at
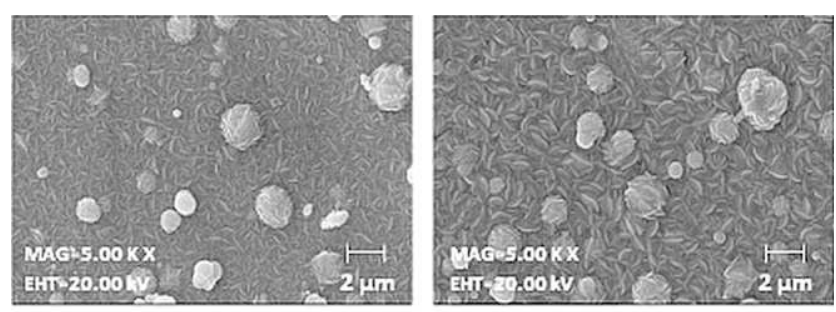

(a)

(b)

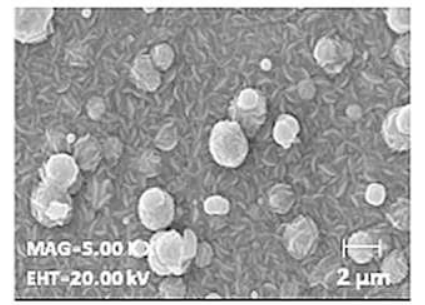

(c)

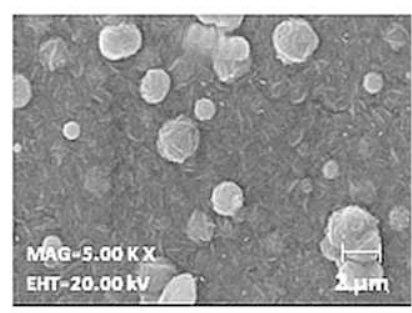

(d)

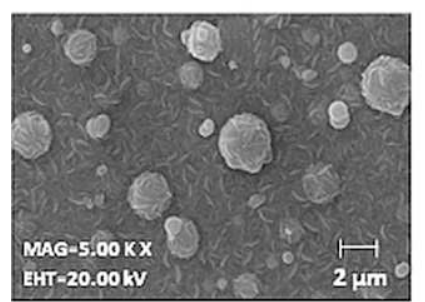

(e)

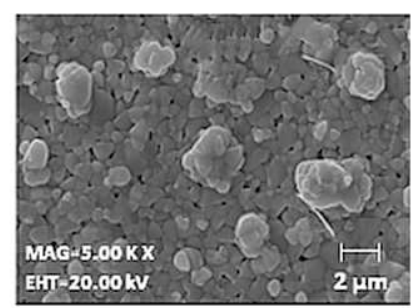

(f)

FIG. 2. The SEM micrographs of the CdS films (a) as-deposited and at (b) $423 \mathrm{~K}$, (c) $523 \mathrm{~K}$, (d) $623 \mathrm{~K}$, (e) $723 \mathrm{~K}$, and (f) $823 \mathrm{~K}$.

$823 \mathrm{~K}$ ). The second one is a shift of the absorption edge toward longer wavelengths. The thickness of the films was calculated from the transmission interference using the following equation:

$$
d=\frac{\lambda_{i} \lambda_{i+1}}{2\left[n\left(\lambda_{i}\right) \lambda_{i+1}-n\left(\lambda_{i+1}\right) \lambda_{i}\right]},
$$

where $d$ is the film thickness, and $n\left(\lambda_{i}\right)$ and $n\left(\lambda_{i+1}\right)$ are the refractive indices at the two adjacent maxima (or minima) at $\lambda_{i}$ and $\lambda_{i+1}{ }^{36}$ The thickness of the $\mathrm{CdS}$ film increases linearly with a growth rate of $180 \mathrm{~nm} / \mathrm{h}$, Fig. 4.

The wavelength dependent linear absorption coefficient $\alpha$ of the as-deposited and annealed CdS films was analyzed to determine the optical band gap of the film 
and the nature of the optical transitions involved by using this equation:

$$
I_{\mathrm{t}}(d, h v)=I_{\mathrm{o}} e^{-\alpha(h v) d},
$$

where $d$ is the thickness, $h v$ is photon energy, and $I_{\mathrm{t}}$ and $I_{\mathrm{o}}$ are the intensities of the transmitted and incident light, respectively. Tauc ${ }^{37}$ identified three distinct regions in the absorption spectrum of amorphous semiconductors: (i) the weak-absorption tail which originates from defects and impurities, (ii) the exponential edge region (approximately between $1 \mathrm{~cm}^{-1}$ and $10^{4} \mathrm{~cm}^{-1}$ ) which is related to the structural randomness of the glassy materi-

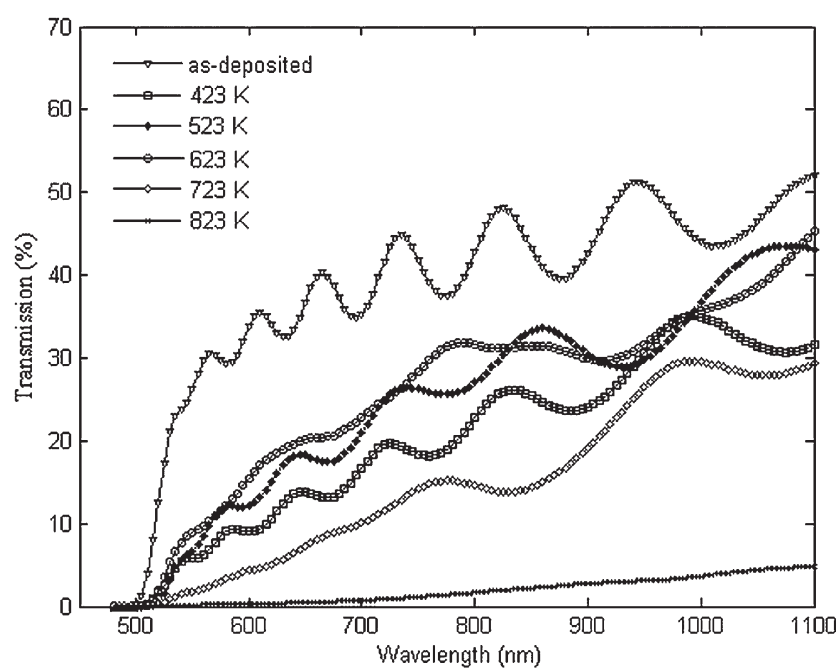

FIG. 3. The transmittance versus wavelength for the as-deposited and the annealed CdS films.

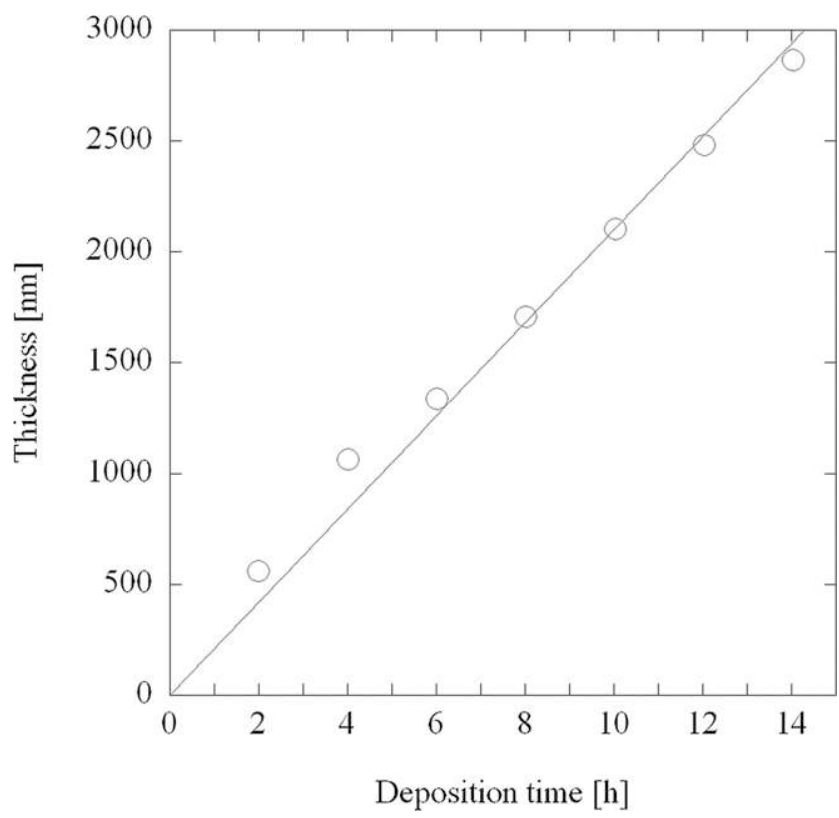

FIG. 4. Time dependence of the thickness for CdS films as a function of coating number. al, and (iii) the high absorption region which determines the optical energy gap. In the edge region, the absorption coefficient $\alpha(h v)$ is well described by the exponential:

$$
\alpha=\alpha_{0} \exp \left(h v / E_{0}\right),
$$

known as the Urbach law. ${ }^{38}$ Here $\alpha_{0}$ is a constant, $h v$ is the incident photon energy, and $E_{0}$ is called the Urbach energy, which characterizes the slope of the exponential edge region and is the width of the band tails of the localized states. The Urbach tail is usually ascribed to the optical electronic transitions between the extended states and the near edge localized states. The formation of localized states with energies at the boundaries of the energy gap is one of the effects of the structural disorder on the electronic structure of amorphous materials. This is the reason why the Urbach energy $\left(E_{0}\right)$ is frequently used as a measure of the degree of structural disorder. $E_{0}$ is given by the relation below:

$$
E_{0}=\left[\frac{d(\ln (\alpha))}{d(h v)}\right]^{-1} .
$$

The $\ln (\alpha)$ value is a function of $h v$ in the photon energy region where $\alpha_{\mathrm{o}}<10^{4} \mathrm{~cm}^{-1}$ as given in Fig. 5 . The value of $E_{0}$ is calculated from the slope of the linear plot illustrated in Fig. 5. These values are listed in Table II. In the high absorption region (where absorption is associated with interband transitions), the form of the absorption coefficient $\alpha(h v)$ was given in quadratic form by Tauc et al. $^{37}$ and discussed in more general terms by Mott and Davis, ${ }^{39}$ who use the equation of the form:

$$
\alpha(h v)=A\left(h v-E_{\mathrm{g}}\right)^{n} / h v,
$$

where $A$ is a constant, $\alpha$ is the absorption coefficient, $h v$ is the photon energy, and $n$ is a constant equal to $1 / 2$

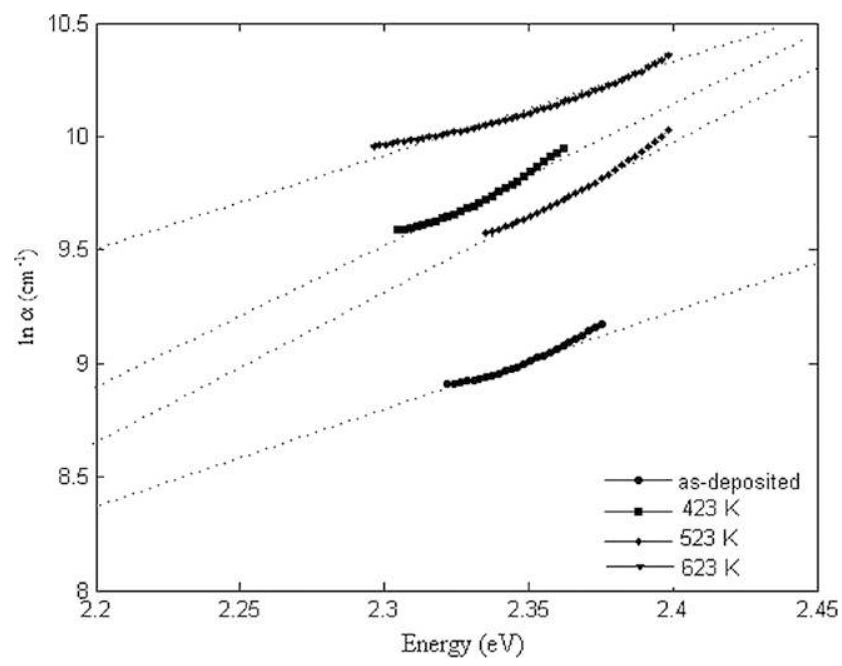

FIG. 5. Graph of $\ln (\alpha)$ versus $h v$ for the as-deposited and the annealed CdS films. 
TABLE II. The optical parameters of as-deposited and annealed CdS films. The films were grown at $70{ }^{\circ} \mathrm{C}$. These parameters were calculated using the transmittance data. The absorption and extinction coefficient were calculated at $\lambda=550 \mathrm{~nm}$.

\begin{tabular}{cccccc}
\hline \hline & & & & \multicolumn{2}{c}{$\begin{array}{c}\text { Activation energy } \\
(\mathrm{eV})\end{array}$} \\
\cline { 3 - 6 } Annealing temperature $(\mathrm{K})$ & $E_{\mathrm{g}}(\mathrm{eV})$ & Urbach tail $\left(E_{\mathrm{o}}\right)(\mathrm{eV})$ & Absorption coefficient $\left(\times 10^{4} \mathrm{~cm}^{-1}\right)$ & Extinction coefficient & $E_{\mathrm{g}} / 2$ \\
\hline As-deposited & 2.42 & 0.20 & 0.6684 & 0.029 & 1.21 \\
423 & 2.40 & 0.19 & 1.4227 & 0.062 & 1.20 \\
523 & 2.38 & 0.16 & 1.3542 & 0.059 & 1.19 \\
623 & 2.37 & 0.14 & 1.2103 & 0.053 & 0.36 \\
723 & 2.33 & 0.18 & 2.0034 & 0.088 & 1.19 \\
823 & 2.28 & 0.21 & 3.1517 & 0.140 & 0.24 \\
\hline
\end{tabular}

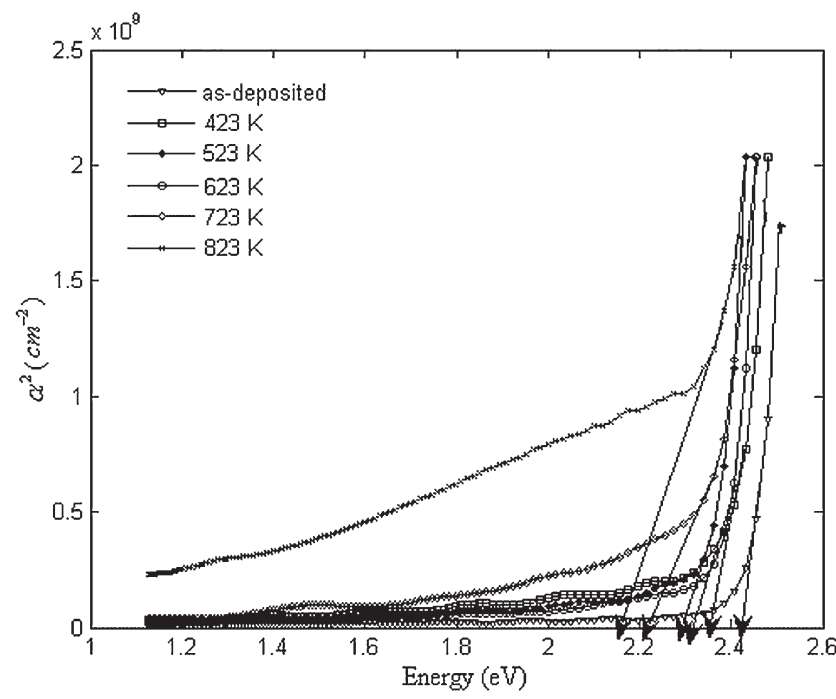

FIG. 6. The $\alpha^{2}$ versus $h v$ for the as-deposited and the annealed CdS films.

for a direct band gap semiconductor. The graph of $\alpha^{2}$ versus $h v$ is given in Fig. 6 and the value of the energy where $\alpha=0$ is the band gap energy $E_{\mathrm{g}}$. It can be seen in Fig. 6 that the absorption edge of the annealed films has shifted toward longer wavelengths with increasing annealing temperature. Also, it is obvious that the band gap energy of the as-deposited film is $2.42 \mathrm{eV}$ and systematically decreases to $2.28 \mathrm{eV}$ for the film annealed at $823 \mathrm{~K}$ (Table II), which is in agreement with the literature. ${ }^{9,21,40}$ At high temperature $(823 \mathrm{~K})$ the film is degraded in terms of optical absorption at the forbidden region. Figure 7 shows the changes in the crystallite size and band gap energy depending on the annealing temperature. It is obvious that an increase in the crystallite size gives rise to a decrease in band gap energy. The extinction coefficient

$$
k=\frac{\alpha \lambda}{4 \pi},
$$

of the CdS films was obtained taking into account the $\alpha$ values at $\lambda=550 \mathrm{~nm}$ for the as-deposited and the annealed CdS films (Table II). The increase of the extinc- tion coefficient with increasing annealing temperature is paralleled by the change in the absorbance of the films.

\section{Electrical properties}

The electrical conductivity measurements of the films have been performed in the temperature range $300 \mathrm{~K} \leq$ $T \leq 570 \mathrm{~K}$. The electrical conductivity of the films was determined with Eq. (8) as follows:

$$
\sigma=\frac{1}{G} \frac{I}{V}
$$

where $\sigma$ is the electrical conductivity, $G$ is the correction factor which depends on the shape and thickness of the film, $I$ is the current through the film and $V$ is the potential drop.

Electrical conductivity increases exponentially with increasing temperature, confirming the semiconducting nature of the film shown in Fig. 8. An increase in temperature removes disorder by decreasing lattice defects, which otherwise act as scattering centers for electronic charges. Therefore, fewer electrons scatter from grain boundaries, which leads to an increase of Arrhenius type electrical conductivity. The electrical conductivity varies from $2.0 \times 10^{-5}$ to $9 \times 10^{-1}(\Omega-\mathrm{m})^{-1}$, and increases with temperature. The conductivities of the as-deposited and annealed films at $523 \mathrm{~K}$ and $623 \mathrm{~K}$ are about $10^{-2}$ and increase up to $10^{-1}$ for the film annealed at $423 \mathrm{~K}$ which shows the highest conductivity. In this film, the exponential behavior starts at a lower temperature, around $425 \mathrm{~K}$. For the annealed film at $723 \mathrm{~K}$, the conductivity is about $10^{-3}$, while the film annealed at $823 \mathrm{~K}$ is on the order of $10^{-4}$. This low conductivity can be attributed to the discontinuity of the grain contacts. The activation energy of the films has been determined by following the relation

$$
\sigma=\sigma_{0} \exp \left(E_{\mathrm{a}} / k_{\mathrm{B}} T\right),
$$

where $\sigma_{0}$ is pre-exponential factor, $k_{\mathrm{B}}$ is the Boltzmann constant, $E_{\mathrm{a}}$ is the activation energy, $T$ is the temperature listed in Table II, and they are in agreement with literature values. ${ }^{7,24}$ It is found that $E_{\mathrm{a}}$ decreases from $0.40 \mathrm{eV}$ to $0.19 \mathrm{eV}$ with increasing annealing temperature, except 


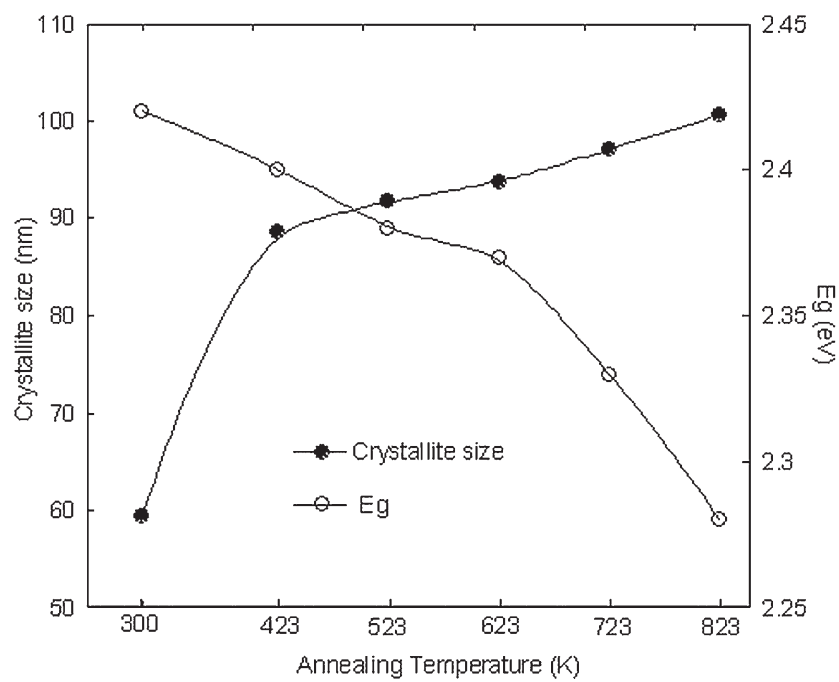

FIG. 7. The changes in the crystallite size and the optical band gap energy of the films depending on annealing temperature.
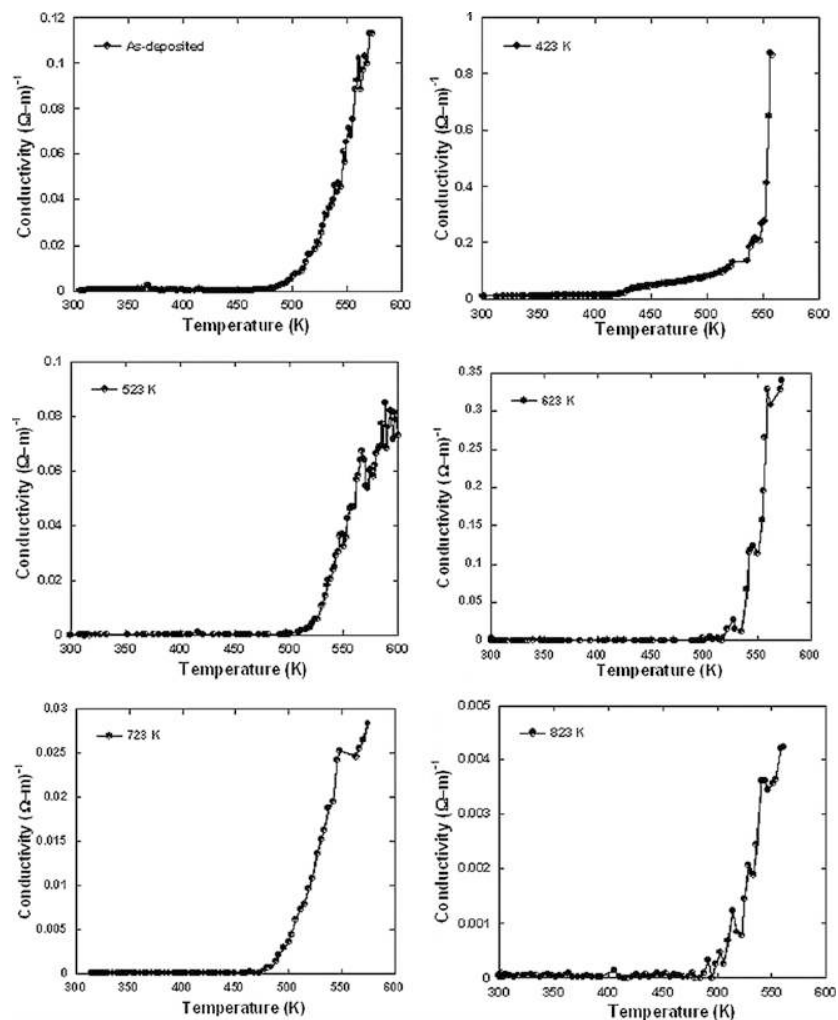

FIG. 8. The temperature dependence of the electrical conductivity of as-deposited and annealed CdS films.

for the film annealed at $523 \mathrm{~K}$, shown in Fig. 9. These values are low compared to the values from the optical measurements $\left(E_{\mathrm{g}} / 2\right)$, Table II. The low activation energies obtained from the resistance measurements indicate doped levels (trapped levels or additional energy levels) due to the presence of impurity atoms in the forbidden gap of the semiconducting thin films. Impurities and

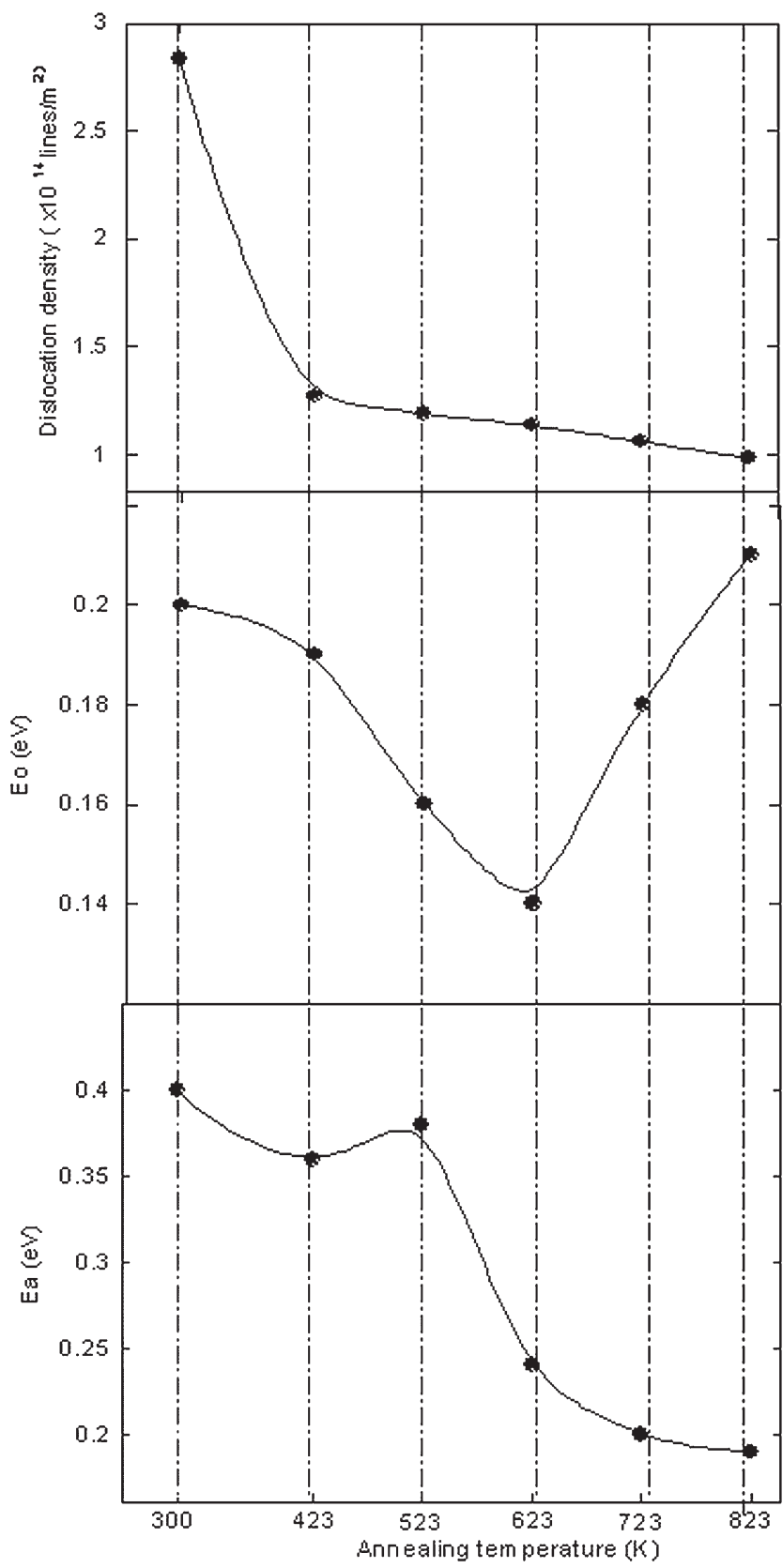

FIG. 9. The changes in the dislocation density, Urbach energy and activation energy of the films depending on annealing temperature.

imperfections drastically affect the electrical properties of a semiconductor. ${ }^{31,41}$ It is also shown in Fig. 9 that the changes in the dislocation density and the Urbach energy go along with the activation energy depending on the annealing temperature. Since the Urbach energy is a measure of disorder, the structure of the films prepared at $623 \mathrm{~K}$ can therefore be considered as the one with the highest structural integrity and order, at least on the scale relevant for optical transitions. The continuously decreasing band gap and the decreasing activation energy are responsible to a large extent for the structural 
integrity of the films particularly for high annealing temperature $T>623 \mathrm{~K}$.

\section{CONCLUSION}

The as-deposited CdS film shows a mixture of 50\% hexagonal and $50 \%$ cubic phases where the hexagonal phase becomes dominant upon annealing. This goes along with increasing crystallite size and a reduction of the dislocation and strain of the films. Structural phase transformation from the metastable cubic phase to the stable hexagonal phase is observed at $823 \mathrm{~K}$. The changes are likely of an entirely structural nature, and not of a chemical nature. There is a red shift effect of the transmission spectrum after annealing, which means that there is some decrease of the band gap energy after annealing (from $2.42 \mathrm{eV}$ to $2.28 \mathrm{eV}$ ). In addition to that, the Urbach tail of the absorption edge decreases with increasing annealing temperature, and increases again at $T>623 \mathrm{~K}$. The absorption and the extinction coefficient calculated at $\lambda=550 \mathrm{~nm}$ show strongly temperature dependent behavior. The film annealed at $423 \mathrm{~K}$ shows the highest conductivity having crystallite size around $88 \mathrm{~nm}$. The temperature dependence of electrical conductivity of the film increases nonlinearly with increasing temperature. The nonlinearity of the evolution of the Urbach energy versus annealing temperature, that is, the fact that there is a minimum in the intermediate temperature range at around $623 \mathrm{~K}$, will require further study to determine its microscopic origin.

\section{ACKNOWLEDGMENTS}

The authors would like to thank M.S. Chemist M. Fatih Emen (at Mersin University) for his help during the annealing process. The financial support by the Erciyes University research fund (contract No. FBA-07041) is gratefully acknowledged. Financial support for A.B. and S.E. by the European Union MIRG No. CT2006-042095 and the Swiss NSF No. 200021-116688 are acknowledged.

\section{REFERENCES}

1. D.S. Reddy, B. Kang, S. Yu, K.R. Gunasekhar, K.N. Rao, A. Divya, and P.S. Reddy: Microstructure, optical and photoluminescence properties of simple thermal evaporated $\mathrm{CdS}$ nanocrystalline films. J. Optoelectron. Adv. Mater. 9(12), 3747 (2007).

2. T. Uchihara, H. Abe, M. Matsumura, and H. Tsubomura: Photocatalytic hydrogen evolution from aqueous solutions of sodium sulfite using platinum-loaded $\mathrm{CdS}_{1-x} \mathrm{Se}_{x}$ mixed crystal powder. Bull. Chem. Soc. Jpn. 62(4), 1042 (1989).

3. J. Pantoja Enriquez and X. Mathew: Influence of the thickness on structural, optical and electrical properties of chemical bath deposited CdS thin films. Sol. Energy Mater. Sol. Cells 76, 313 (2003).

4. H. Zhang, X. Ma, and X.D. Yang: Effects of complexing agent on CdS thin films prepared by chemical bath deposition. Mater. Lett. 58, 5(2003).
5. S. Tiwari and S. Tiwari: Development of CdS based stable thin film photo electrochemical solar cells. Sol. Energy Mater. Sol. Cells 90, 1621 (2006).

6. A. Romeo, D.L. Batzer, H. Zogg, C. Vignali, and A.N. Tiwari: Influence of CdS growth process on structural and photovoltaic properties of CdTe/CdS solar cells. Sol. Energy Mater. Sol. Cells 67, 311 (2001).

7. J. Hiie, T. Dedova, V. Valdna, and K. Muska: Thermal annealing effect on structural and electrical properties of chemical bath-deposited CdS films. Thin Solid Films 511-512, 443 (2006).

8. R. Devi, P.K. Kalita, P. Purakayastha, and B.K. Sarma: Growth and transport properties of nanocrystalline $\mathrm{CdS}$ thin film. J. Optoelectron. Adv. Mater. 10(11), 3077 (2008).

9. K. Ravichandran and P. Philominathan: Investigations on microstructural and optical properties of CdS films fabricated by a lowcost, simplified spray technique using perfume atomizer for solar cell applications. Sol. Energy 82, 1062 (2008).

10. S.A. Mahmoud, A.A. Ibrahim, and A.S. Riad: Physical properties of thermal coating CdS thin films using a modified evaporation source. Thin Solid Films 144, 372 (2000).

11. H. Uda, H. Yonezawa, Y. Ohtsubo, M. Kosaka, and H. Sonomura: Thin CdS films prepared by metalorganic chemical vapor deposition. Sol. Energy Mater. Sol. Cells 75, 219 (2003).

12. J. Herrero, M.T. Gutierrez, C. Guillen, J.M. Dona, M.A. Martinez, A.M. Chaparro, and R. Bayon: Photovoltaic windows by chemical bath deposition. Thin Solid Films 361-362, 28 (2000).

13. P. Roy and S.K. Srivastava: A new approach towards the growth of cadmium sulphide thin film by CBD method and its characterization. Mater. Chem. Phys. 95, 235 (2006).

14. B. Pradhan, A.K. Sharma, and A.K. Ray: Conduction studies on chemical bath-deposited nanocrystalline CdS thin films. J. Cryst. Growth 304, 388 (2007).

15. F. Chen, W. Jie, and X. Cai: Effects of supersaturation on CdS film growth from dilute solutions on glass substrate in chemical bath deposition process. Thin Solid Films 516, 2823 (2008).

16. J.N. Ximello-Quiebras, G. Contreras-Puente, J. Aguilar-Hernandez, G. Santana-Rodriguez, and A. Arias-Carbajal Readigos: Physical properties of chemical bath deposited CdS thin films. Sol. Energy Mater. Sol. Cells 82, 263 (2004).

17. H.E. Maliki, J.C. Bernede, S. Marsillac, J. Pinel, X. Castel, and J. Pouzet: Study of the influence of annealing on the properties of CBD-CdS thin films. Appl. Surf. Sci. 205, 65 (2003).

18. J.P. Enriquez and X. Mathew: Influence of the thickness on structural, optical and electrical properties of chemical bath deposited CdS thin films. Sol. Energy Mater. Sol. Cells 76, 313 (2003).

19. J.H. Lee: Influence of substrates on the structural and optical properties of chemically deposited CdS films. Thin Solid Films 515, 6089 (2007).

20. L. Wenyia, C. Xuna, C. Qiulonga, and Z. Zhibin: Influence of growth process on the structural, optical and electrical properties of CBD-CdS films. Mater. Lett. 59, 1 (2005).

21. S. Prabahar and M. Dhanam: CdS thin films from two different chemical baths-Structural and optical analysis. J. Cryst. Growth 285, 41 (2005)

22. S.N. Sharma, R.K. Sharma, K.N. Sood, and S. Singh: Structural and morphological studies of chemical bath-deposited nanocrystalline CdS films and its alloys. Mater. Chem. Phys. 93, 368 (2005).

23. M. Kostoglou, N. Andritsos, and A.J. Karabelas: Progress towards modelling the $\mathrm{CdS}$ chemical bath deposition process. Thin Solid Films 387, 115 (2001).

24. B.R. Sankapal, R.S. Mane, and C.D. Lokhande: Deposition of $\mathrm{CdS}$ thin films by the successive ionic layer adsorption and reaction (SILAR) method. Mater. Res. Bull. 35, 177 (2000).

25. R.B. Kale and C.D. Lokande: Band gap shift, structural characterization and phase transformation of CdSe thin films from 
nanocrystalline cubic to nanorod hexagonal on air annealing. Semicond. Sci. Technol. 1, 20 (2005).

26. K.L. Chopra: Thin Film Phenomenon (McGraw-Hill, New York, 1969).

27. Polycrystalline Semiconductors: Physical Properties and Applications, edited by G. Harbeke (Springer, Berlin, 1985).

28. G.I. Rusu, M.E. Popa, G.G. Rusu, and I. Salaoru: On the electronic transport properties of polycrystalline ZnSe films. Appl. Surf. Sci. 222, 218 (2003)

29. R.S. Rusu and G.I. Rusu: On the electrical and optical characteristics of CdO thin films. J. Optoelectron. Adv. Mater. 7(2), 823 (2005).

30. S. Erat, H. Metin, and M. Ari: Influence of the annealing in nitrogen on the XRD, EDX, SEM and electrical properties of chemical bath deposited CdSe thin films. Mater. Chem. Phys. 111(1), 114 (2008).

31. H. Metin, F. Sat, S. Erat, and M. Ari: Cadmium sulphide thin films grown by CBD: The effect of thermal annealing on the structural, electrical and optical properties. J. Optoelectron. Adv. Mater. 10(10), 2622 (2008).

32. H. Metin and R. Esen: Annealing studies on CBD grown CdS thin films. J. Cryst. Growth 258(1-2), 141 (2003).

33. B.G. Wagh and D.M. Bhagat: Some studies on preparation and characterization of cadmium sulphide films. Curr. Appl. Phys. 4, 259 (2004)
34. Y.A. Kalandaragha, M.B. Muradov, R.K. Mamedov, M. Behboudnia, and A. Khodayari: Structural, compositional and optical characterization of water soluble CdS nanoparticles synthesized by ultrasonic irradiation. J. Optoelectron. Adv. Mater. Rapid Commun. 2 (1), 42 (2008).

35. D. Patidar, N.S. Saxena, K. Sharma, and T.P. Sharma: Conduction mechanism in CdZnS thick films. J. Optoelectron. Adv. Mater. Rapid Commun. 1(7), 329 (2007).

36. J.N. Pankove: Optical Processes in Semiconductors (Dover, New York, 1971).

37. J. Tauc: Amorphous and Liquid Semiconductors, edited by J. Tauc (Plenum Press, London and New York, 1974), p. 175.

38. F. Urbach: The long-wavelength edge of photographic sensitivity and of the electronic absorption of solids. Phys. Rev. 92, 1324 (1953).

39. N.F. Mott and E.A. Davis: Electronic Processes in Non-Crystalline Materials (Clarendon, Oxford, UK, 1979), p. 287.

40. V. Bilgin, S. Kose, F. Atay, and I. Akyuz: The effect of substrate temperature on the structural and some physical properties of ultrasonically sprayed CdS films. Mater. Chem. Phys. 94, 103 (2005).

41. R.K. Nkum, A.A. Adimado, and H. Totoe: Band gap energies of semiconducting sulphides and selenides. Mater. Sci. Eng., B 55, 102 (1998). 